\title{
The cat as a model for human obesity: insights into depot-specific inflammation associated with feline obesity
}

\author{
H. Van de Velde ${ }^{1 *}$, G. P. J. Janssens ${ }^{1}$, H. de Rooster ${ }^{2}$, I. Polis ${ }^{2}$, I. Peters ${ }^{3}$, R. Ducatelle ${ }^{4}$, \\ P. Nguyen ${ }^{5}$, J. Buyse $^{6}$, K. Rochus ${ }^{1}$, J. Xu$^{1}$, A. Verbrugghe ${ }^{1}$ and M. Hesta ${ }^{1}$ \\ ${ }^{1}$ Laboratory of Animal Nutrition, Department of Nutrition, Genetics and Ethology, Faculty of Veterinary Medicine, \\ Ghent University, Heidestraat 19, 9820 Merelbeke, Belgium \\ ${ }^{2}$ Department of Medicine and Clinical Biology of Small Animals, Ghent University, Merelbeke, Belgium \\ ${ }^{3}$ School of Veterinary Science, University of Bristol, Bristol, UK \\ ${ }^{4}$ Department of Pathology, Bacteriology and Avian Diseases, Ghent University, Merelbeke, Belgium \\ ${ }^{5}$ Nutrition and Endocrinology Unit, National College of Veterinary Medicine, Food Science and Engineering, \\ LUNAM Université, Oniris, Nantes, France \\ ${ }^{6}$ Division of Livestock-Nutrition-Quality, Department of Biosystems, Catholic University of Leuven, Leuven, Belgium \\ (Submitted 9 August 2012 - Final revision received 7 December 2012 - Accepted 30 December 2012 - First published online 23 May 2013)
}

\begin{abstract}
According to human research, the location of fat accumulation seems to play an important role in the induction of obesity-related inflammatory complications. To evaluate whether an inflammatory response to obesity depends on adipose tissue location, adipokine gene expression, presence of immune cells and adipocyte cell size of subcutaneous adipose tissue (SAT) and visceral adipose tissue (VAT) were compared between lean and obese cats. Additionally, the present study proposes the cat as a model for human obesity and highlights the importance of animal models for human research. A total of ten chronically obese and ten lean control cats were included in the present study. Body weight, body condition score and body composition were determined. T-lymphocyte, B-lymphocyte, macrophage concentrations and adipocyte cell size were measured in adipose tissue at different locations. Serum leptin concentration and the mRNA expression of leptin and adiponectin, monocyte chemoattractant protein- 1 , chemoligand- $5, I L-8, T N F-\alpha$, interferon- $\gamma, I L-6$ and $I L-10$ were measured in blood and adipose tissues (abdominal and inguinal SAT, and omental, bladder and renal VAT). Feline obesity was characterised by increased adipocyte cell size and altered adipokine gene expression, in favour of pro-inflammatory cytokines and chemokines. Consequently, concentration of T-lymphocytes was increased in the adipose tissue of obese cats. Alteration of adipose tissue was location dependent in both lean and obese cats. Moreover, the observed changes were more prominent in SAT compared with VAT.
\end{abstract}

Key words: Adipokines: Adipose tissue: Obesity: mRNA expression

The prevalence of human obesity, which is currently about $30 \%$ in the USA, has increased dramatically over the last 30 years, consequently increasing medical costs for the treatment of related disease conditions ${ }^{(1-3)}$. Both visceral adipose tissue (VAT) and subcutaneous adipose tissue (SAT) are affected in human obesity, but VAT shows the strongest correlation with inflammatory markers and risk factors for the metabolic syndrome $^{(4)}$.

Numerous studies in rodents have already provided insights into the complex onset of obesity-related disorders; however, despite this abundant information, several topics, including the mechanism by which visceral obesity contributes more to the pro-inflammatory profile, are still subject to further investigation. As morbid obesity can be rapidly induced in rats, they may not be the most accurate model for human obesity research, which represents a more chronic obesity ${ }^{(5,6)}$. Dogs and cats are suggested to be more reliable models for human endocrine disorders than rodents, as the variation in the degree of obesity corresponds more to human obesity and genetic homology between humans and companion animals is greater than to rodents ${ }^{(5,7,8)}$.

As in humans, feline overweight and obesity have become a rising problem with a prevalence ranging between 19 (Western Australia) and $52 \%(\mathrm{UK})^{(9,10,11)}$. Obese cats tend to have a sedentary inactive lifestyle with offered food on an ad libitum basis, and obesity is mostly associated with

Abbreviations: BW, body weight; CCL-5, chemoligand-5; cDNA, complementary DNA; hpf, high-power field; IHC, immunohistochemical; MCP-1, monocyte chemoattractant protein-1; SAT, subcutaneous adipose tissue; VAT, visceral adipose tissue.

*Corresponding author: H. V. de Velde, fax +32 26478 48, email vandevelde.hannelore@gmail.com 
owners who 'humanise' their pet ${ }^{(12)}$. Additional similarities between cats and humans are postulated, as diabetes mellitus in cats strongly resembles human type 2 diabetes and dyslipidaemia also occurs with feline obesity ${ }^{(8,13)}$. Whether obesity causes an inflammatory state in cats that might predispose to diabetes mellitus, dyslipidaemia and lower urinary tract disorders has not been investigated so far ${ }^{(14)}$. In one study, a higher mRNA expression of TNF- $\alpha$ was demonstrated in the SAT of obese cats compared with lean cats ${ }^{(15)}$. Another study, however, concluded that obesity or subsequent weight loss did not alter plasma acute-phase proteins in cats $^{(16)}$ and that systemic immune competence of obese cats showed no impairment compared with lean cats ${ }^{(17)}$. So far, no study has evaluated the impact of adipose tissue location on the inflammatory response to obesity in the domestic cat, which might elucidate a possible link between locationdependent inflammation and obesity-related disorders.

The present study evaluated adipokine mRNA expression and morphological features of SAT (abdominal and inguinal) and VAT (omental, bladder and renal) in chronically obese compared with lean control cats. The present hypothesis stated that the adipocyte cell size of chronically obese cats is larger compared with lean cats, and that adipose tissue in feline obesity attracts macrophages and T-and B-lymphocytes, consequently inducing an inflammatory response. Furthermore, location-dependent alterations of adipose tissue due to feline obesity are expected. As mentioned above, the results of the present feline study will help in determining the future suitability of cats as a model for human obesity.

\section{Experimental methods}

\section{Animals and diet}

A total of ten lean control (four males: one intact and three neutered; six females: one intact and five neutered) and ten chronically obese cats (five males and five females, all neutered) were included in the study. Obese cats were chronically obese $(>2$ years, except for the youngest cat that was only obese for 6 months). Obesity was a naturally occurring phenomenon and was not experimentally induced by the diet. All cats were group housed with an equal distribution of age in each group (lean cats: 5.8 ( $\mathrm{SE}$ 3.5) years; obese cats: 6.6 ( $\mathrm{SE} 3.0$ ) years). All the cats underwent a general clinical examination and blood analysis (complete blood count and serum biochemistry) to ensure optimal health. At 4 weeks before the sampling procedure, an adaptation period was included, in which all cats received a commercial dry cat food (Friskies for neutered cat: rabbit and vegetables, Nestlé Belgilux NV; Nestlé Purina PetCare) that contained no fish oil (Table 1). Food was offered in groups of approximately eight cats at maintenance energy requirement (calculated for each cat individually and the total amount of food was calculated per group: lean cats $418 \mathrm{~kJ} / \mathrm{kg}$ body weight $(\mathrm{BW})^{0.67}$ and obese cats $544 \mathrm{~kJ} / \mathrm{kg} \mathrm{BW}^{0.4}$ ) according to the National Research Council guidelines ${ }^{(18)}$. Cats were weighed twice weekly to ensure a constant BW. Drinking water was available ad libitum.
Table 1. Analysed nutrient and labelled ingredient composition of the experimental diet ${ }^{\star}$

\begin{tabular}{lc}
\hline Nutrient (\% DM) & \\
\hline Diethyl ether extract & 8.6 \\
Crude protein & 32 \\
Crude fibre & 1.5 \\
Crude ash & $6 \cdot 2$ \\
NFE† & 52 \\
TDF & 14 \\
ME (kJ/100 g as fed)‡ & 1383
\end{tabular}

NFE, N-free extract; TDF, total dietary fibre; ME, metabolisable energy.

* Ingredient list: grain, vegetable protein extracts, meat and animal by-products, vegetable by-products, oils and fats, yeast, minerals and vegetables.

† Derived by subtracting crude protein, diethyl ether extract, crude ash and crude fibre content from 100 .

$\ddagger$ Estimated using a four-step calculation ${ }^{(18)}$.

\section{Study design}

After the 4-week adaptation period, BW and body condition score were determined using a nine-point body condition scale, in which 1/9 reflects cachexia, 5/9 optimal body condition and $9 / 9$ obesity ${ }^{(19)}$. Body composition was measured using the $\mathrm{D}_{2} \mathrm{O}$ dilution method ${ }^{(20)}$. Under general anaesthesia, a fasting blood sample was taken from the jugular vein for the determination of serum leptin and the mRNA expression of adipokines. Samples of SAT (abdominal and inguinal) and VAT (omental, bladder and renal) were collected surgically for the determination of the mRNA expression of adipokines, and for histological and immunohistochemical (IHC) evaluation. The study design was approved by the ethical committee of the Faculty of Veterinary Medicine, Ghent University, Belgium and was in accordance with institutional and national guidelines for the care and use of animals (EC2011/131).

\section{Anaesthetic protocol}

After intramuscular pre-medication with $20 \mu \mathrm{g} / \mathrm{kg}$ of dexmedetomidine (Dexdomitor ${ }^{\circledR}$; Janssen Animal Health), anaesthesia was induced with $1-2 \mathrm{mg} / \mathrm{kg}$ of propofol intravenously given to effect (Propovet ${ }^{\circledR}$; Abbott Laboratories). Additional analgesia was provided by $0 \cdot 1 \mathrm{mg} / \mathrm{kg}$ of methadone intravenously (Mephenon ${ }^{\circledR}$; Sterop). After endotracheal intubation, anaesthesia was maintained with isoflurane (Isoflo ${ }^{\circledR}$; Abbott Laboratories) in $\mathrm{O}_{2}$ given to effect using a paediatric circular system. During the procedure, all cats received a lactated Ringer's solution (Ringer lactate; B. Braun Medical NV/SA) at $10 \mathrm{ml} / \mathrm{kg}$ intravenously, and they were continuously monitored through pulse oximetry (N-20PA Portable Pulse Oximeter, Nellcor Puritan Bennett Inc.) and capnography (Capnomac Uttima; Datex Engstorn). After surgery, 0.05 ml atipamezole (Antisedan ${ }^{\circledR}$; Pfizer Animal Health) was administered intramuscularly and post-operative analgesia was provided by an additional dose of methadone in combination with $0.3 \mathrm{mg} / \mathrm{kg}$ of meloxicam (Metacam ${ }^{\circledR}$; Boehringer Ingelheim Vetmedica $\mathrm{GmbH}$ ) subcutaneously.

\section{Blood and adipose tissue sampling}

A fasting blood sample was taken from the jugular vein and transferred to either a serum blood tube (Vacuette Z Serum 
Sep Clot Activator; Greiner bio-one) to measure leptin concentration or a PAXgene Blood RNA Tube (PreAnalytiX $\mathrm{GmbH}$ ) and stored at $-20^{\circ} \mathrm{C}$ until analysis. Furthermore, samples of SAT (abdominal and inguinal) and VAT (omental, bladder and renal) were collected surgically through a ventral median celiotomy, utilising new biopsy material per location to prevent RNA contamination from previous samples, for the determination of the mRNA expression of several adipokines and for the microscopic evaluation of IHC and haematoxylin-eosin-stained sections. Samples of SAT and VAT were approximately $1 \mathrm{~cm}$ in diameter and were subdivided into pieces with a maximum diameter of $0.5 \mathrm{~cm}$. Adipose tissue samples for mRNA expression were immediately stored in RNAlater tissue storage solution (Sigma-Aldrich). After an overnight incubation at $4^{\circ} \mathrm{C}$, samples were stored at $-20^{\circ} \mathrm{C}$ until analyses were performed. Adipose tissue samples for IHC and haematoxylin-eosin staining were placed in neutral-buffered formalin for $48 \mathrm{~h}$ before embedding in paraffin and sectioning at $5 \mu \mathrm{m}$.

\section{Analytical methods}

Diet. The diet was analysed for DM, ash, crude protein, diethyl ether extract, crude fibre and total dietary fibre. DM and ash content were determined by drying to a constant weight at $103^{\circ} \mathrm{C}$ and combustion at $550^{\circ} \mathrm{C}$, respectively. Crude protein $(6 \cdot 25 \times \mathrm{N})$ was determined using the Kjeldahl method (ISO 5983-1, 2005) and diethyl ether extract was analysed with the Soxhlet method (ISO 1443, 1973). Crude fibre and total dietary fibre were determined using the Association of Official Analytical Chemists methods ${ }^{(21,22)}$.

Determination of body composition. Determination of body fat mass and lean mass was achieved by the $\mathrm{D}_{2} \mathrm{O}$ dilution technique and Fourier transform IR spectroscopy as described previously in dogs and cats ${ }^{(20,23)}$. At $2 \mathrm{~h}$ before the start of the procedure, cats were deprived of food and water and a first blood sample (EDTA plasma tube, Vacuette K3E $\mathrm{K}_{3}$ EDTA; Greiner bio-one) was taken from the jugular vein. Then, $500 \mathrm{mg} / \mathrm{kg} \mathrm{BW}$ of isotopic $99.9 \% \mathrm{D}_{2} \mathrm{O}$ (Euriso-Top SA) were injected subcutaneously and a second blood sample (EDTA plasma tube) was taken $4 \mathrm{~h}$ later. Plasma was obtained by centrifugation $(15 \mathrm{~min}, 1620 \mathrm{~g})$ and immediately stored at $-20^{\circ} \mathrm{C}$ until analyses. Samples were analysed with Fourier transform IR spectroscopy as described previously ${ }^{(20)}$.

Determination of serum leptin concentration. Serum was obtained by centrifugation ( $15 \mathrm{~min}, 1620 \mathrm{~g}$ ) and immediately stored at $-20^{\circ} \mathrm{C}$ until analyses were performed. Serum leptin was analysed using a commercially available multi-species RIA test kit (catalogue no. XL-85K; Linco Research, Inc.). This kit was developed to quantify leptin in the serum of several species, and has been validated for use in cats ${ }^{(23)}$.

Immunohistochemical staining of $5 \mu \mathrm{m}$ paraffin-embedded sections. IHC staining on $5 \mu \mathrm{m}$ paraffin-embedded sections of SAT and VAT was performed as described previously by Van der Heyden et al. ${ }^{(24)}$, with some modifications. Primary monoclonal antibodies CD3 (A045201; Dako), CD20 (RB9013-P; Klinipath) and MAC387 (ab22506; Abcam) were applied at a dilution of 1:100, for the identification of
T-lymphocytes, B-lymphocytes and macrophages, respectively. A positive control (inflamed intestinal tissue) was included in each test run to ensure specificity. Sections for CD3 and CD20 staining were treated in a pressure cooker with 0.01 M-citric acid ( $\mathrm{pH} \mathrm{6.0)} \mathrm{(CBB} \mathrm{999;} \mathrm{Klinipath)} \mathrm{in} \mathrm{distilled}$ water in a microwave oven $(15 \mathrm{~min}$ at $850 \mathrm{~W}$ followed by $15 \mathrm{~min}$ at $300 \mathrm{~W})$. Staining was performed in an automated

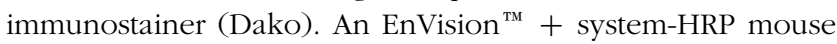
and rabbit (DAB) kit (K4007; Dako) was used to visualise MAC387 (anti-mouse) and CD3 and CD20 lymphocytes (antirabbit). This kit includes endogenous peroxidase block and antibody diluents (S302283; Dako).

Quantitative interpretation of immunohistochemical and haematoxylin-eosin staining. Stained sections were evaluated with a light microscope (Olympus BH2; Olympus Corporation). Adipose tissue was evaluated at the highest magnification of $400 \times$ (high-power field; hpf), which corresponds to $0.2 \mathrm{~mm}^{2}$. The number of $\mathrm{CD}^{+}$T-lymphocytes, $\mathrm{CD} 20^{+}$B-lymphocytes and macrophages were evaluated in the IHC-stained sections and were counted in ten hpf. Adipocytes were evaluated in the haematoxylin-eosin-stained sections and were counted in five hpf. The mean number of both adipocytes and immune cells was expressed per $\mathrm{mm}^{2}$. Adipocyte size and the diameter of adipocytes $(\mu \mathrm{m})$ were calculated by the following equations:

Surface area of adipocytes $\left(\mu \mathrm{m}^{2}\right)$

$=$ surface area of hpf/number of counted adipocytes per hpf,

Radius of adipocytes $(\mu \mathrm{m})=\sqrt{\text { surface area of adipocytes } / \Pi}$,

Diameter of adipocytes $(\mu \mathrm{m})=$ radius $\times 2$.

RNA isolation from blood and adipose tissue samples. Total RNA was isolated from the PAXgene tube using the PAXgene blood kit (PreAnalytix, GmbH) and from $100 \mathrm{mg}$ fat ( $\pm 10 \mathrm{mg}$ ) using the Qiagen RNeasy Lipid Kit (Qiagen N.V.), according to the manufacturer's instructions including the oncolumn DNase digestion step. Fat samples were homogenised in a Tissuelyser (Qiagen), using $1 \mathrm{ml}$ of lysis buffer from the extraction kit and a $5 \mathrm{~mm}$ steel ball bearing in a $2 \mathrm{ml}$ SafeLock tube (Eppendorf), with shaking at $20 \mathrm{~Hz}$ for $2 \mathrm{~min}$. RNA was eluted in $2 \times 50 \mu \mathrm{l}$ of nuclease-free water with further DNase digestion carried out using RQ1 RNase-Free DNase (Promega Corporation) according to the manufacturer's instructions with the sample incubated for $15 \mathrm{~min}$ at room temperature. In order to remove DNase and reaction buffer from the purified RNA (both blood and fat), it was passed through the Macherey-Nagel NucleoSpin RNA 8 Isolation Kit (ABgene Limited) using the RNA clean-up protocol and was eluted in $2 \times$ $40 \mu \mathrm{l}$ of elution buffer (10 mm-Tris- $\mathrm{HCl}, \mathrm{pH} 8$ 8).

The quantity and quality of the resulting RNA was assessed by automated gel electrophoresis (Experion; Bio-Rad Laboratories). RNA was stored at $-70^{\circ} \mathrm{C}$ before use.

Primer and hydrolysis probe design. Primers and probes were designed using Primer $3^{(25)}$ (www-genome.wi.mit.edu/ cgi-bin/primer/primer3_www.cgi) and M-Fold using the felinespecific GenBank sequences for potential housekeeping genes: 
$\beta$-actin $(A C T B), \beta$-2-microglobulin (B2M), hydroxymethyl-bilane synthase (HMBS), hypoxanthine phosphoribosyl-transferase 1 (HPRT1), ribosomal protein L32 (RPL32), ribosomal protein $\mathrm{S} 7$ (RPS7) and tyrosine 3-monooxygenase/tryptophan 5-monooxygenase activation protein, zeta polypeptide $(Y W A Z)$, as well as adiponectin $(A D I P)$, leptin $(L E P), I L-8$, monocyte chemoattractant protein-1 (MCP-1), chemoligand-5 $(C C L-5)$ as described previously (Table 2) ${ }^{(26)}$. IL-6-, IL-10-, interferon- $\boldsymbol{\gamma}$ - and TNF- $\alpha$-specific assays were the same as those published previously (Table 2$)^{(27,28)}$.

Real-time PCR. Synthesis of complementary DNA (cDNA) was carried out with $500 \mathrm{ng}$ of random hexamers using the ImProm-II Reverse Transcription System (Promega Corporation) with 300-500 ng (fat) and 600-1000 ng (blood) of total RNA (as measured by Experion; Bio-Rad Laboratories) in a final volume of $20 \mu \mathrm{l}$. All reactions were prepared in duplicate according to the manufacturer's instructions, giving a final magnesium chloride concentration of $3 \mathrm{~mm}$ with sample incubations carried out in a PTC-200 DNA engine (Bio-Rad Laboratories). All cDNA were diluted to a final volume of $120 \mu \mathrm{l}$ (1:6 dilution) using EB buffer (10 mM Tris- $\mathrm{HCl}, \mathrm{pH}$ 8.4; Qiagen Limited) and then stored at $-20^{\circ} \mathrm{C}$ for future use. No template controls were performed by the addition of nuclease-free water in place of RNA.

Quantitative PCR was performed using GoTaq Colourless Master Mix (Promega Corporation) and $0.2 \mu \mathrm{M}$ of each primer, $0 \cdot 1 \mu \mathrm{M}$ of probe $\operatorname{Rox}^{\mathrm{TM}}$ (1:5000; Invitrogen), $4.5 \mathrm{~mm}-\mathrm{MgCl}_{2}$ and $5 \mu \mathrm{l}$ of diluted cDNA in a final volume of $25 \mu \mathrm{l}$. Sample incubations were performed in an MxPro $3005 \mathrm{P}$ (Agilent) at $95^{\circ} \mathrm{C}$ for $2 \mathrm{~min}$, followed by forty-five cycles at $95^{\circ} \mathrm{C}$ for $10 \mathrm{~s}$ and $60^{\circ} \mathrm{C}$ for $30 \mathrm{~s}$ during which the fluorescence data were collected. Threshold values $\left(C_{\mathrm{t}}\right)$ for the samples were calculated using MxPro qPCR software (version 4.1) with the multiple experiment analyser with run-to-run variations in $C_{\mathrm{t}}$ normalised using a positive control of known copy number and ROX as a passive reference dye. The absence of genomic contamination of the RNA samples was confirmed before the RT reactions, and none of the samples showed evidence of amplifiable genomic DNA with the glyceraldehyde-3-phosphate dehydrogenase quantitative PCR assay. One quantitative PCR was run for each RT repeat, resulting in two $C_{\mathrm{t}}$ values for each RNA sample.

In order to determine the most appropriate housekeeper genes for the study, all eight potential genes were quantified in twenty cDNA samples from the blood and twenty-five cDNA samples from fat. A mean $C_{\mathrm{t}}$ value was calculated for each sample using the two measured $C_{\mathrm{t}}$ values for each cat for each of the potential housekeeper genes. The mean $C_{\mathrm{t}}$ value was converted to a relative copy number value using the $E^{\Delta C_{\mathrm{t}}}$ method ( $E$ being the reaction efficiency as determined from a standard curve) with $\Delta C_{\mathrm{t}}$ values calculated relative to the sample with the largest $C_{\mathrm{t}}$ (fewest gene copies). The geNorm VBA (visual basics for applications) applet for Microsoft Excel was used to determine the most stable genes from the set of the tested genes ${ }^{(28)}$. The three most stable housekeeper genes for the blood samples were $B 2 M$, HPRT1 and YWAZ and for the fat samples were RPS 7, RPL32 and YWAZ. As RPS7 and RPL32 are both ribosomal proteins,

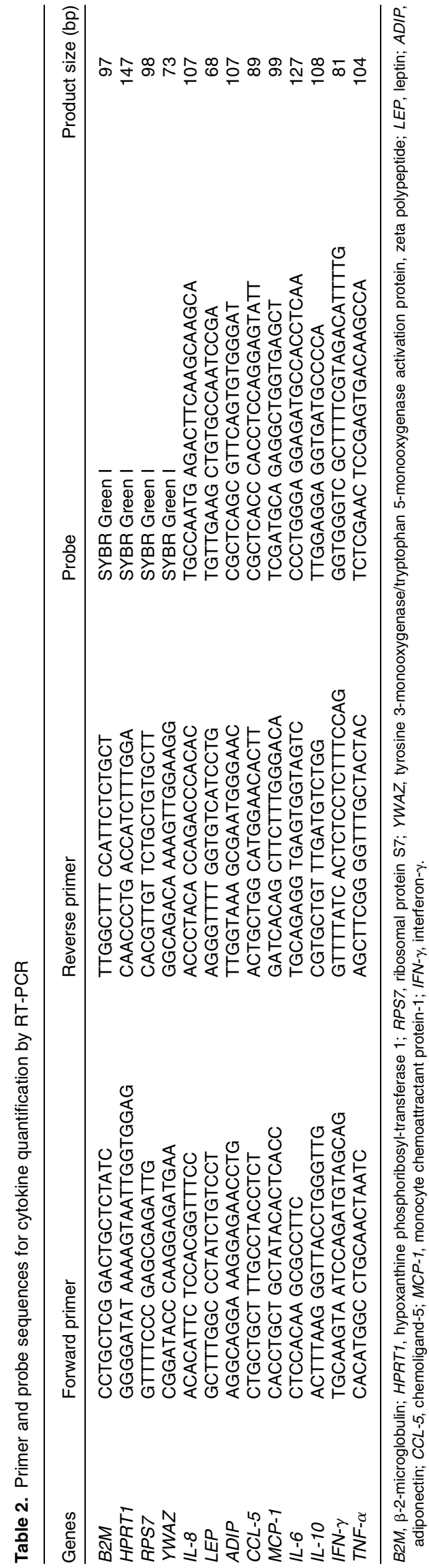


Table 3. $P$ values* (univariate ANOVA with group $\dagger$ and location $\ddagger$ as fixed factors and cat§ as the random factor)

\begin{tabular}{lrrrr}
\hline & Group & Location & Interaction & Cat \\
\hline Adipocyte cell size & $<0.001$ & $<0.001$ & 0.096 & $<0.001$ \\
T-lymphocytes/mm $\mathrm{mm}^{2}$ & 0.039 & 0.605 & 0.813 & 0.121 \\
B-lymphocytes/mm & 0.252 & 0.362 & 0.222 & 0.154 \\
Macrophages/mm ${ }^{2}$ & 0.238 & 0.513 & 0.984 & 0.592 \\
Leptin mRNA gene expression & 0.011 & 0.003 & 0.457 & $<0.001$ \\
Adiponectin mRNA gene expression & 0.039 & $<0.001$ & 0.488 & $<0.001$ \\
MCP-1 mRNA gene expression & 0.043 & $<0.001$ & 0.680 & 0.018 \\
CCL-5 mRNA gene expression & 0.004 & $<0.001$ & 0.068 & 0.002 \\
IL-8 mRNA gene expression & 0.713 & 0.044 & 0.961 & 0.135 \\
TNF- $\alpha$ mRNA gene expression & 0.059 & 0.143 & 0.095 & 0.155 \\
IFN- $\gamma$ mRNA gene expression & 0.052 & 0.366 & 0.469 & 0.019 \\
IL-6 mRNA gene expression & 0.331 & 0.007 & 0.598 & 0.015 \\
IL-10 mRNA gene expression & 0.995 & 0.001 & 0.974 & 0.020 \\
\hline
\end{tabular}

MCP-1, monocyte chemoattractant protein-1; CCL-5, chemoligand-5; IFN- $\gamma$, interferon- $\gamma$.

${ }^{*} P$ values are analysed with a univariate ANOVA, significance is set at $P<0.05$.

$\dagger$ Group (ten obese $v$. ten lean cats) is a fixed factor.

‡Location (abdominal and inguinal subcutaneous adipose tissue, and omental, bladder and renal visceral

adipose tissue) is a fixed factor

$\S$ Cat nested in group is a random factor.

the next most stable housekeeper (HPRT1) was used in place of RPL32 to ensure that stable housekeeper genes with a variety of functions were used for normalisation. The three selected housekeeper genes were then used to normalise the results for the other genes quantified in all the samples tested.

Relative expression data for each of the mRNA targets were calculated using the qBase applet for Microsoft Excel (http:// medgen.ugent.be/qbase/). This applet calculates a relative copy number for each sample using individual assay efficiencies, normalised against the measured housekeeper mRNA, using the methods described by Vandesompele et al. ${ }^{(28)}$. The sample with the fewest gene copies (latest $C_{\mathrm{t}}$ value) is given a relative copy number of 1 and all other samples are given values relative to this sample.

\section{Statistical analysis}

BW, body condition score, body composition, serum leptin concentration and mRNA expression in the blood were analysed using a one-way ANOVA, comparing the results of both groups. Histological, IHC and adipose tissue mRNA expression results were analysed using a univariate crossed

Table 4. Body weight, body condition score (BCS), fat mass and serum leptin concentration in ten obese and ten lean cats

(Mean values with their standard errors)

\begin{tabular}{|c|c|c|c|c|c|}
\hline & \multicolumn{2}{|c|}{ Obese cats } & \multicolumn{2}{|c|}{ Lean cats } & \multirow[b]{2}{*}{$P^{*}$} \\
\hline & Mean & SE & Mean & SE & \\
\hline Body weight (kg) & $6 \cdot 2$ & 0.4 & $3 \cdot 9$ & $0 \cdot 2$ & $<0.001$ \\
\hline BCS (nine-point scale) & 8 & 0.3 & 5 & 0.1 & $<0.001$ \\
\hline Fat mass $(\mathrm{kg})$ & 2.5 & 0.4 & 0.9 & 0.9 & 0.001 \\
\hline Fat mass (\%) & 39 & $3 \cdot 3$ & 25 & $2 \cdot 3$ & 0.003 \\
\hline $\begin{array}{l}\text { Serum leptin } \\
\text { concentration (ng/ml) }\end{array}$ & 12 & 2.9 & $4 \cdot 3$ & $0 \cdot 8$ & 0.019 \\
\hline
\end{tabular}

${ }^{*} P$ values were analysed with a one-way ANOVA, significance is set at $P<0.05$. factor ANOVA, with group and location as fixed factors and cat nested in group as the random factor. $P$ values for group, location, cat nested in group and interaction effects are given in Table 3. A Bonferroni post hoc test was performed to distinguish differences annotated to biopsy location. Significance is set at $P<0.05$ and values are given as means with their standard errors.

\section{Results}

As expected, BW $(P<0 \cdot 001)$, body condition score $(P<0 \cdot 001)$, serum leptin concentration $(P=0 \cdot 019)$ and fat mass $(P=0 \cdot 001$ $(\mathrm{kg})$ and $P=0.003(\%)$ ) (Table 4) of obese cats were higher compared with lean cats.

Obese cats had larger adipocyte size compared with lean cats $(P<0.001)$ and adipocytes were the smallest in bladder VAT $(P<0.001)$ in both obese and lean cats (Fig. 1(A)). More T-lymphocytes were present in the adipose tissue of obese compared with lean cats $(P=0.039$; Fig. $1(\mathrm{~B}))$, whereas the number of B-lymphocytes (Fig. 1(C)) and macrophages (Fig. 1(D)) did not differ between the lean and obese cats. Adipose tissue location did not influence T-lymphocyte, B-lymphocyte and macrophage counts (Fig. 1(B)-(D)).

Leptin mRNA expression was higher in the adipose tissue $(P=0.011)$ and blood $(P=0.040)$ of obese cats compared with lean cats (Fig. 2(A) and (G), respectively). Compared with omental and bladder VAT, abdominal SAT showed a higher expression of leptin for both groups $(P=0.003)$. In contrast, the expression of total adiponectin mRNA was lower in the adipose tissue of obese cats compared with lean cats ( $P=0.039)$. In both groups, the highest adiponectin expression was demonstrated for renal VAT $(P<0.001$; Fig. 2(B)). Yet, body condition did not influence adiponectin expression in the blood (Fig. 2(G)).

TNF- $\alpha$ and interferon- $\gamma$ tended to have a higher mRNA expression in the adipose tissue of obese cats compared with lean cats $(P=0.059$ and 0.052 , respectively), whereas 
(A)

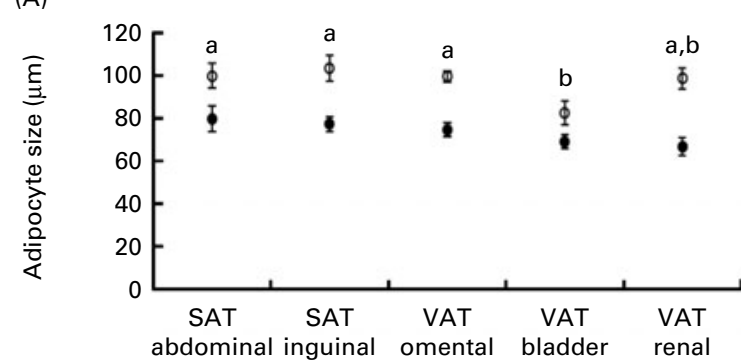

(C)

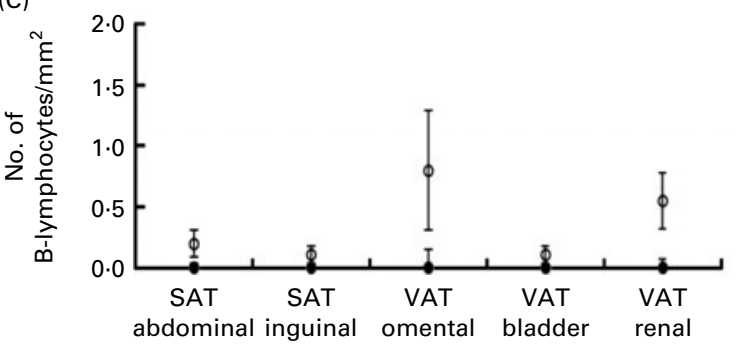

(B)

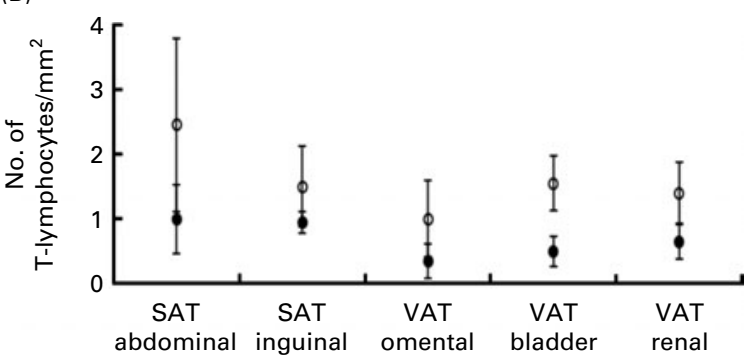

(D)

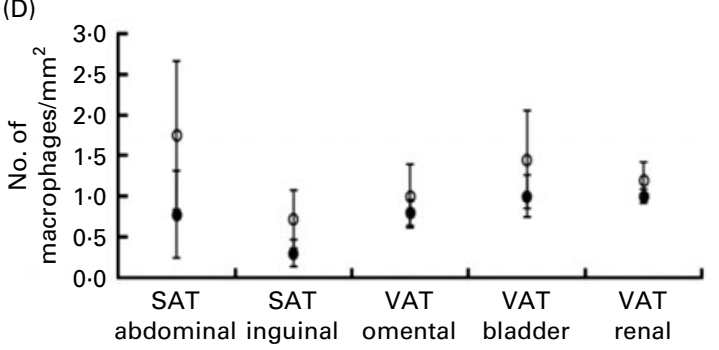

Fig. 1. (A) Adipocyte size, (B) number of T-lymphocytes $/ \mathrm{mm}^{2}$, (C) number of B-lymphocytes $/ \mathrm{mm}^{2}$ and (D) number of macrophages $/ \mathrm{mm}^{2}$ in subcutaneous adipose tissue (SAT) and visceral adipose tissue (VAT) in ten obese $(O)$ and ten lean $(\bullet)$ cats. Values are means, with their standard errors represented by vertical bars. ${ }^{\mathrm{a}, \mathrm{b}}$ Mean values with unlike letters were significantly different between the adipose tissue locations $(P<0.05)$.

the expression of $I L-6$ and $I L-10$ mRNA did not differ between the adipose tissue of both groups (Fig. 2(C)-(F)). Abdominal SAT of both groups had a higher expression of $I L-6$ mRNA compared with omental VAT $(P=0 \cdot 007$; Fig. 2(D)), and the expression of $I L-10$ mRNA of both obese and lean cats was higher in omental VAT compared with bladder and renal VAT $(P=0.001 ;$ Fig. $2(\mathrm{~F}))$. In the blood, no differences between the lean and obese cats were detected for the expression of $T N F-\alpha$, interferon- $\gamma, I L-6$ and $I L-10$ mRNA (Fig. 2(G)).

The expression of mRNA encoding the chemokines CCL-5 and MCP-1 did not differ between the lean and obese cats in the blood (Fig. 3(D)), but was elevated in the adipose tissue of obese cats compared with lean cats $(P=0.004$ and $P=0.043$, respectively), and in both groups, the expression of $C C L-5$ and $M C P-1$ mRNA differed among the adipose tissue locations $(P<0.001)$ (Fig. 3(A) and (B), respectively). Abdominal SAT showed a greater expression of CCL-5 mRNA compared with bladder and renal VAT, and inguinal SAT had a higher expression compared with omental, bladder and renal VAT. The expression of $M C P-1$ mRNA was larger in inguinal SAT compared with omental, bladder and renal VAT. $I L-8$ mRNA revealed no difference in mRNA expression in the blood and adipose tissue between the groups (Fig. 3(C)).

\section{Discussion}

The present study was designed to evaluate the inflammatory response of adipose tissue in obese cats compared with lean cats. It was hypothesised that chronically obese cats possess larger adipocytes and local inflammation in adipose tissue. As in humans, location-dependent alteration of gene expression and inflammatory profile was expected in obese cats, elucidating new insights for both human and feline research

\section{Feline obesity is characterised by increased adipocyte cell size}

Technically, obesity is defined as a pathological condition in which an excessive amount of adipose tissue is deposited ${ }^{(29)}$, which can be either due to cellular hypertrophy (enlargement of cell size) or hyperplasia (many small cells) ${ }^{(30)}$. In humans, hypertrophy of adipocytes causes alteration in the production of adipokines, leading to chronic low-grade inflammation ${ }^{(31)}$. In contrast, hyperplasia has been shown to exert a protective effect against obesity-related disorders, in particular insulin resistance $^{(30)}$.

To our knowledge, no information exists on adipocyte cell size in cats. In the present study, adipocytes of obese and lean cats reached approximately 100 and $75 \mu \mathrm{m}$, respectively. These values are similar to a recent canine study of diet-induced obesity ${ }^{(32)}$, in which adipocytes of VAT, larger than $75 \mu \mathrm{m}$, were highly associated with a prediction of insulin resistance. In addition, adipocytes of obese humans achieve a size of approximately $100 \mu \mathrm{m}^{(33)}$. A limitation of the present study is the method of measuring adipose cell size. Adipose tissue was stained with haematoxylin-eosin and assessed with a morphological approach by counting the number of cells per hpf, which is probably a less sensitive technique than the isolation and individual measurement of adipocytes. Despite this limitation, a fairly good similarity in adipocyte size with human and canine studies was achieved. However, insulin sensitivity was not assessed in the present study. 
(A)

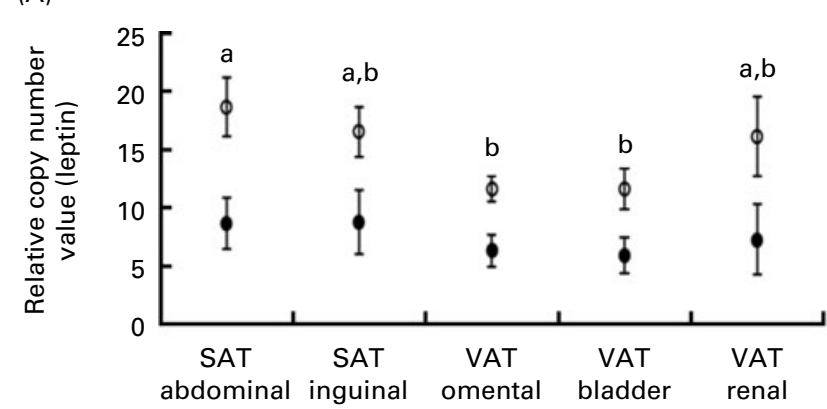

(C)

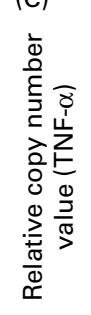

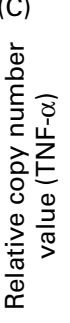

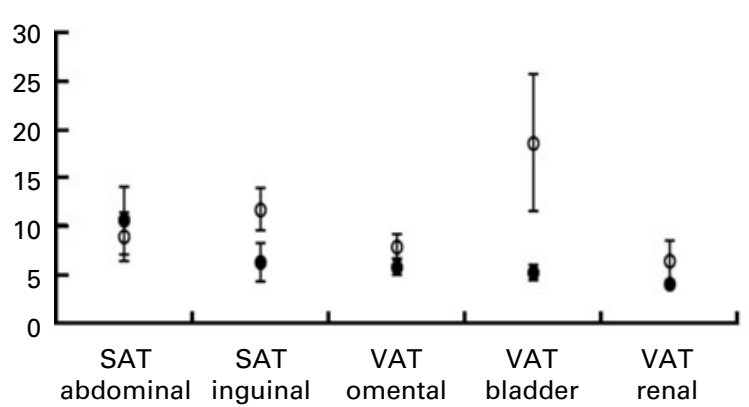

(B)

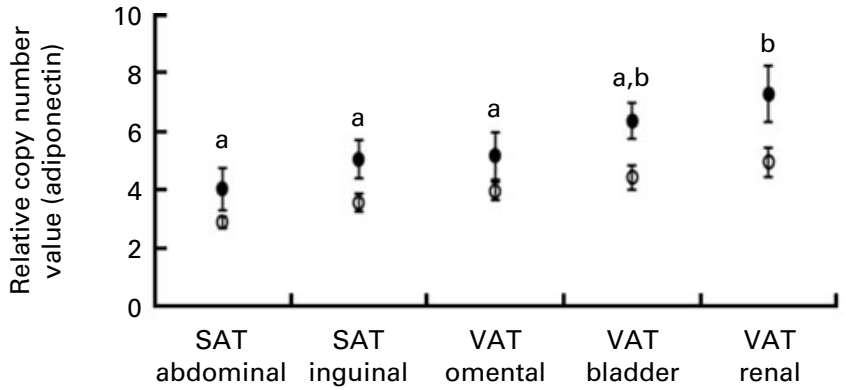

(D)

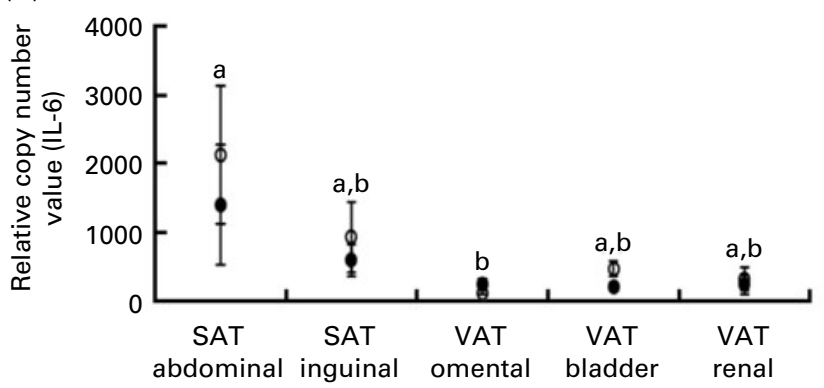

(F)

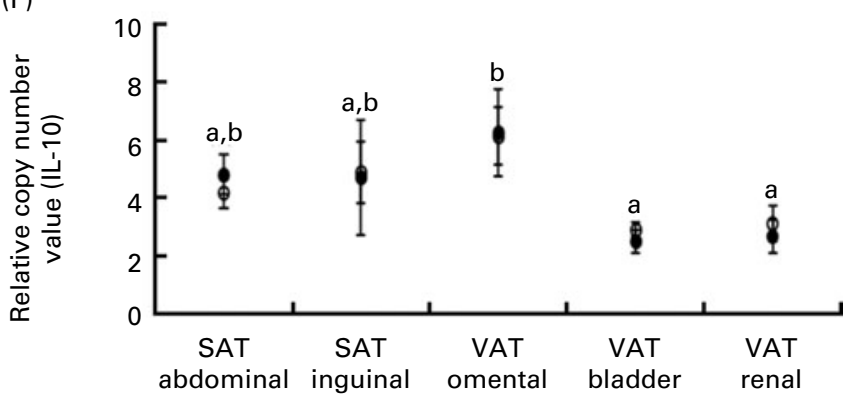

(E)

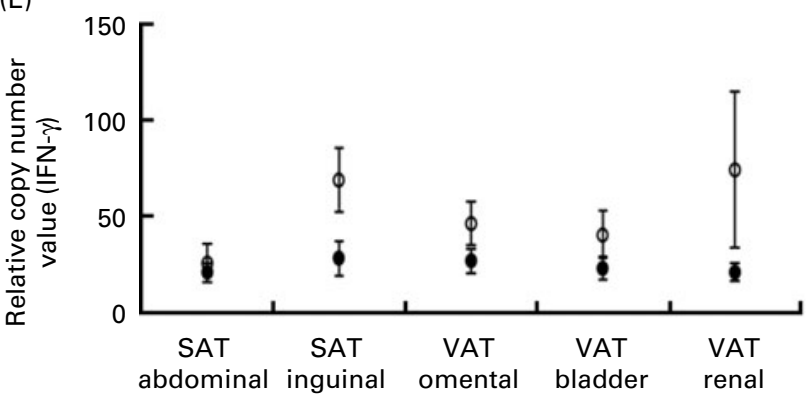

(G)

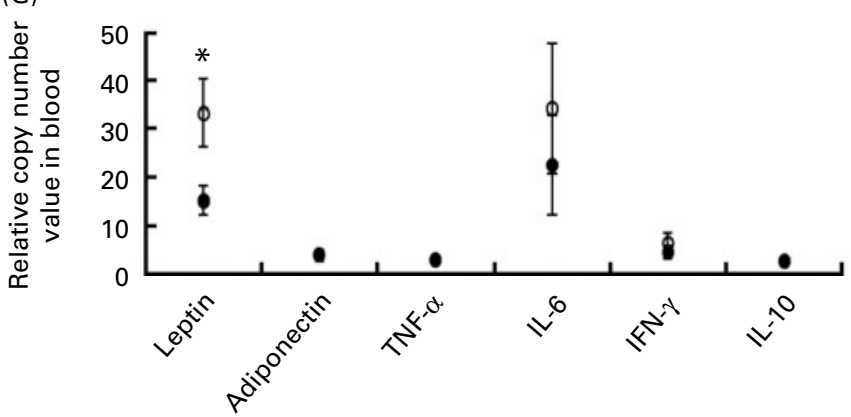

Fig. 2. Relative copy number value of (A) leptin, (B) adiponectin, (C) TNF- $\alpha$, (D) IL-6, (E) interferon- $\gamma$ (IFN- $\gamma$ ) and (F) IL-10 in subcutaneous adipose tissue (SAT) and visceral adipose tissue (VAT) and (G) relative copy number value of the above-mentioned adipokines in the blood in ten obese $(O)$ and ten lean $(\bullet)$ cats. Values are means, with their standard errors represented by vertical bars. ${ }^{a, b}$ Mean values with unlike letters were significantly different between the adipose tissue locations $(P<0.05)$. ${ }^{*}$ Mean values were significantly different between the two groups $(P<0.05)$.

Gene expression of adipokines is altered in feline obesity and induces inflammation and attraction of

\section{T-lymphocytes into adipose tissue}

To our knowledge, mRNA expression of leptin and adiponectin has not previously been measured in the adipose tissue of cats. Gene expressions of these adipokines were increased and decreased, respectively, in obese cats compared with lean cats. The pattern of expression of these genes was as expected, since feline obesity is characterised by systemic hyperleptinaemia and hypo-adiponectinaemia ${ }^{(23,34,35,36)}$. However, adiponectin is manifested in several forms with 
(A)

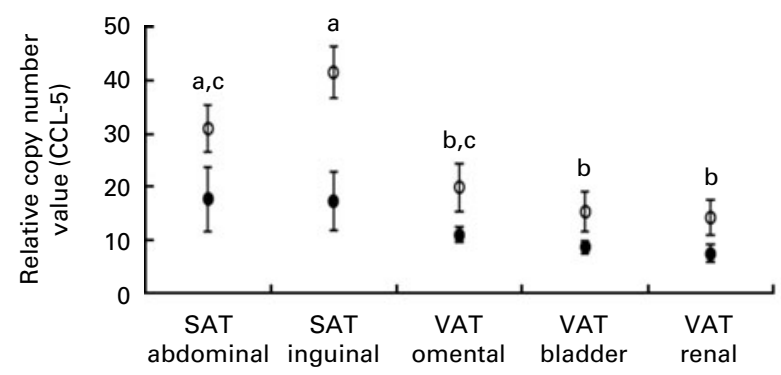

(C)

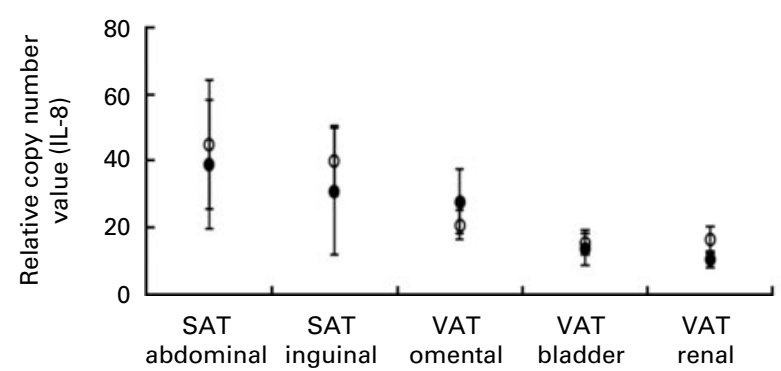

(B)

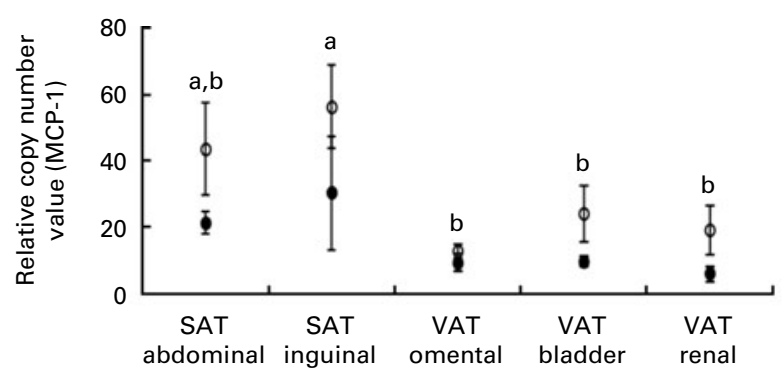

(D)

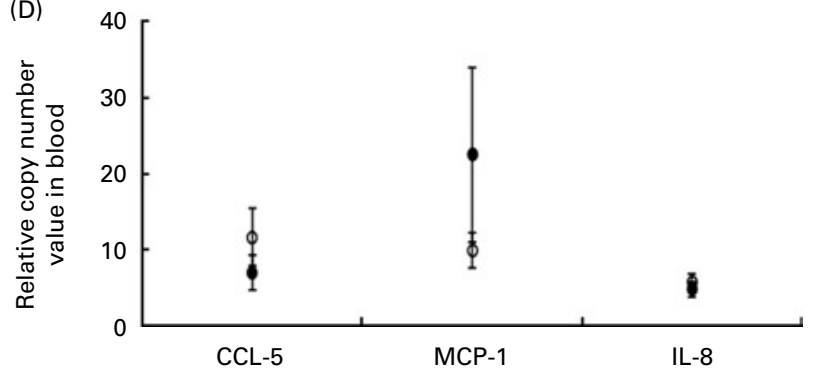

Fig. 3. Relative copy number value of (A) chemoligand-5 (CCL-5), (B) monocyte chemoattractant protein-1 (MCP-1) and (C) IL-8 in subcutaneous adipose tissue (SAT) and visceral adipose tissue (VAT) and (D) relative copy number value of the above-mentioned chemokines in the blood in ten obese (O) and ten lean ( $)$ cats. Values are means, with their standard errors represented by vertical bars. ${ }^{a, b, c}$ Mean values with unlike letters were significantly different between the adipose tissue location $(P<0.05)$.

different molecular weights, of which high-molecular-weight adiponectin has been suggested to be the most active form in humans ${ }^{(37)}$. Although low-molecular-weight and high-molecular-weight adiponectin have been measured in dogs and cats $^{(38,39)}$, their function has yet to be clarified in these species ${ }^{(40)}$. Validated species-specific techniques are mostly based upon the measurement of total adiponectin in dogs and cats $^{(16,41)}$.

Gene expression of chemokines reflects the 'homing' capacity (chemoattraction of immune cells by chemokines) of inflamed adipose tissue. Indeed, gene expressions of $M C P-1$, a chemokine attracting monocytes/macrophages, and $C C L-5$, a chemokine attracting T-lymphocytes, were significantly increased in obese cats compared with lean cats. The higher CCL-5 expression was associated with an increased number of $\mathrm{CD}^{+}$T-lymphocytes in the adipose tissue of obese cats compared with lean cats. Despite the high expression of $M C P-1$ during feline obesity, an increased number of macrophages in the adipose tissue of obese cats compared with lean cats was not demonstrated. Although the presence of macrophages was expected, recent knowledge in rodents illustrates sequential influx of immune cells into the adipose tissue of obese subjects. Cells of adaptive immunity, such as T-lymphocytes, are proposed as initiators of an inflammatory cascade, followed by the production of MCP-1 and the subsequent attraction of macrophages $^{(42)}$. As the number of macrophages was not increased in obese cats, one might suggest that the degree of obesity in the present study was not severe enough to recruit macrophages into adipose tissue. However, the initial inflammatory response set up by T-lymphocytes and the increased expression of chemokines illustrate the ongoing homing of immune cells in these cats. As limited data are available concerning the order of immune cell attraction in obese adipose tissue from human subjects, the outcomes of the present study highlight the importance of this model to illustrate the mechanisms of ongoing obesity development.

Since only a few feline validated reagents are available, serum concentrations of cytokines were not measured and, consequently, the gene expression of cytokines in adipose tissue cannot be compared with the level of proteins. However, the gene expression of adipokines did not differ between the two groups in the blood, except for leptin, indicating the importance of determining mRNA expression of these molecules in adipose tissue. A greater mRNA expression of the pro-inflammatory cytokines TNF- $\alpha$ and interferon- $\gamma$ was noted in the adipose tissue of obese cats compared with lean cats, illustrating a pro-inflammatory profile during feline obesity, similar to human and rodent studies. The expression of $I L-6$ and $I L-10$ mRNA was not different between the adipose tissue of obese and lean cats, but a location-dependent expression was shown for these cytokines. Despite the antiinflammatory profile of IL-10, this cytokine can be co-elevated in human obesity, as a response to the increase of pro-inflammatory cytokines. The absence of increased numbers of macrophages in the adipose tissue of obese cats might explain the unaltered expression of IL-10, since activated cells are co-producers of this cytokine ${ }^{(43)}$. 


\section{Altered gene expression of adipokines and increased cell size highlight the importance of subcutaneous adipose tissue in cats}

Central obesity in humans is known as a state of obesity associated with a highly increased risk of metabolic and inflammatory diseases ${ }^{(4)}$. Until now, it was not known whether obese cats possess a similar profile to humans. By collecting adipose tissue at five different locations (abdominal and inguinal SAT, and omental, bladder and renal VAT), the present study provides valuable information regarding the impact of adipose tissue location on the inflammatory responses seen with feline obesity. This information is valuable since co-morbidities such as diabetes and dyslipidaemia are similar in both humans and cats, and a recent study suggested the cat as a model for human obesity ${ }^{(8)}$. The present study illustrated that adipocyte size in cats is smallest in bladder VAT, irrespective of their state of obesity. In contrast, one study in rats reported larger adipocytes in retroperitoneal adipose tissue compared with mesenterial adipose tissue and $\mathrm{SAT}^{(44)}$. Additionally, both in obese and non-obese human subjects, SAT was characterised by larger cells compared with omental $\operatorname{VAT}^{(45,46)}$.

In the present study in cats, the expression of leptin, $M C P-1$ and $I L-6$ mRNA was higher in SAT compared with VAT in both groups, but differences depended on the location within SAT or VAT. CCL-5, the chemokine attracting T-lymphocytes, tended to illustrate an effect of obesity on adipose tissue location, meaning that this chemokine was increased more prominently in SAT by feline obesity. This is opposite to human obesity since in humans, VAT predominantly contributes to an inflammatory profile and consequently to obesityrelated disorders. This dissimilar location-dependent response between humans and cats might be an interesting topic for further research and might have implications for the treatment of obesity-related disorders such as insulin resistance and diabetes mellitus in cats.

\section{Conclusion}

The present study is the first to illustrate that feline obesity is characterised by increased adipocyte cell size and altered adipokine gene expression. Moreover, the presence of T-lymphocytes in feline obese adipose tissue was demonstrated, which is in parallel with human obesity. However, SAT seems to be more involved in the development of an inflammatory response compared with VAT, which is in contrast with human obesity. The present study extends the knowledge on feline obesity and on the development of its related disorders, and highlights both similarities and differences compared with human obesity.

\section{Acknowledgements}

The present study is within the scope of the postgraduate study of the first author and is funded by the Institute for Promotion of Innovation through Science and Technology in Flanders (IWT Vlaanderen), Belgium, grant no. 083253. The authors would like to thank Nestlé Belgilux NV, Nestlé Purina PetCare (Brussels, Belgium) for providing the cat food. Laura Statius and Saartje Van Beirs are kindly acknowledged for animal care taking and technical assistance, Herman De Rycke, Inge Vaesen and Daniel Vermeulen for performing the food and serum analyses. H. V. d. V. was responsible for the study design and accomplishment, sample analyses and data processing, and manuscript drafting. M. H. and G. P. J. J. were co-responsible for the study design, data processing and manuscript drafting. H. d. R., I. Po. and R. D. were co-responsible for the study accomplishment and manuscript drafting. I. Pe., P. N. and J. B. were co-responsible for the sample analyses and manuscript drafting. K. R., J. X. and A. V. cooperated in the study accomplishment and manuscript drafting. The authors declare no conflict of interest.

\section{References}

1. Finkelstein EA, Trogdon JG, Cohen JW, et al. (2009) Annual medical spending attributable to obesity: payer-and servicespecific estimates. Health Aff (Millwood) 28, w822-w831.

2. James PT (2004) Obesity: the worldwide epidemic. Clin Dermatol 22, 276-280.

3. Ogden CL, Yanovski SZ, Carroll MD, et al. (2007) The epidemiology of obesity. Gastroenterology 132, 2087-2102.

4. Pou KM, Massaro JM, Hoffmann U, et al. (2009) Patterns of abdominal fat distribution: the Framingham Heart Study. Diabetes Care 32, 481-485.

5. Bergman RN, Kim SP, Catalano KJ, et al. (2006) Why visceral fat is bad: mechanisms of the metabolic syndrome. Obesity (Silver Spring) 14, Suppl. 1, 16S-19S.

6. Symonds ME, Sebert S \& Budge H (2011) The obesity epidemic: from the environment to epigenetics - not simply a response to dietary manipulation in a thermoneutral environment. Front Genet 2, 24.

7. Hoenig M (2006) The cat as a model for human nutrition and disease. Curr Opin Clin Nutr Metab Care 9, 584-588.

8. Kooistra HS, Galac S, Buijtels JJ, et al. (2009) Endocrine diseases in animals. Horm Res 71, Suppl. 1, 144-147.

9. Robertson ID (1999) The influence of diet and other factors on owner-perceived obesity in privately owned cats from metropolitan Perth, Western Australia. Prev Vet Med 40, $75-85$.

10. Russell K, Sabin R, Holt S, et al. (2000) Influence of feeding regimen on body condition in the cat. J Small Anim Pract 41, 12-17.

11. Scarlett JM, Donoghue S, Saidla J, et al. (1994) Overweight cats: prevalence and risk factors. Int J Obes Relat Metab Disord 18, Suppl. 1, S22-S28.

12. Kienzle E \& Bergler R (2006) Human-animal relationship of owners of normal and overweight cats. J Nutr 136, 1947S-1950S.

13. Hoenig M, Thomaseth K, Waldron M, et al. (2007) Fatty acid turnover, substrate oxidation, and heat production in lean and obese cats during the euglycemic hyperinsulinemic clamp. Domest Anim Endocrinol 32, 329-338.

14. German AJ (2006) The growing problem of obesity in dogs and cats. J Nutr 136, 1940S-1946S.

15. Hoenig M, McGoldrick JB, deBeer M, et al. (2006) Activity and tissue-specific expression of lipases and tumor-necrosis factor alpha in lean and obese cats. Domest Anim Endocrinol 30, 333-344. 
16. Tvarijonaviciute A, Ceron JJ, Holden SL, et al. (2012) Effects of weight loss in obese cats on biochemical analytes related to inflammation and glucose homeostasis. Domest Anim Endocrinol 42, 129-141.

17. Jaso-Friedmann L, Leary JH III, Praveen K, et al. (2008) The effects of obesity and fatty acids on the feline immune system. Vet Immunol Immunopathol 122, 146-152.

18. National Research Council (2006) Energy. In Nutrient Requirements of Dogs and Cats, pp. 28-48. Washington DC: The National Academies Press.

19. Laflamme D (1997) Development and validation of a body condition score system for cats: a clinical tool. Feline Pract 25, 13-17.

20. Ferrier L, Robert P, Dumon H, et al. (2002) Evaluation of body composition in dogs by isotopic dilution using a lowcost technique, Fourier-transform infrared spectroscopy. J Nutr 132, 1725S-1727S.

21. Association of Official Analytical Chemists (AOAC) (1995) Method 962.09. Determination of crude fibre in feeds. In Methods of Analysis [P Cunnif, editor]. Washington DC: Association of Official Analytical Chemists.

22. Association of Official Analytical Chemists (AOAC) (1995) Method 985.29. Total dietary fibre in foods: enzymatic gravimetric method. In Methods of Analysis [P Cunnif, editor]. Washington DC: Association of Official Analytical Chemists.

23. Backus RC, Havel PJ, Gingerich RL, et al. (2000) Relationship between serum leptin immunoreactivity and body fat mass as estimated by use of a novel gas-phase Fourier transform infrared spectroscopy deuterium dilution method in cats. Am J Vet Res 61, 796-801.

24. Van der Heyden S, Vercauteren G, Daminet S, et al. (2011) Expression of P-glycoprotein in the intestinal epithelium of dogs with lymphoplasmacytic enteritis. J Comp Pathol 145, 199-206.

25. Rozen S \& Skaletsky H (2000) Primer3 on the WWW for general users and for biologist programmers. Methods Mol Biol 132, 365-386.

26. Peters IR, Helps CR, Hall EJ, et al. (2004) Real-time RT-PCR: considerations for efficient and sensitive assay design. J Immunol Methods 286, 203-217.

27. Nguyen VN, Taglinger K, Helps CR, et al. (2006) Measurement of cytokine mRNA expression in intestinal biopsies of cats with inflammatory enteropathy using quantitative realtime RT-PCR. Vet Immunol Immunopathol 113, 404-414.

28. Vandesompele J, De PK, Pattyn F, et al. (2002) Accurate normalization of real-time quantitative RT-PCR data by geometric averaging of multiple internal control genes. Genome Biol 3, RESEARCH0034.

29. Klaus S (2004) Adipose tissue as a regulator of energy balance. Curr Drug Targets 5, 241-250.

30. Hoffstedt J, Arner E, Wahrenberg H, et al. (2010) Regional impact of adipose tissue morphology on the metabolic profile in morbid obesity. Diabetologia 53, 2496-2503.
31. Skurk T, Alberti-Huber C, Herder C, et al. (2007) Relationship between adipocyte size and adipokine expression and secretion. J Clin Endocrinol Metab 92, 1023-1033.

32. Kabir M, Stefanovski D, Hsu IR, et al. (2011) Large size cells in the visceral adipose depot predict insulin resistance in the canine model. Obesity (Silver Spring) 19, 2121-2129.

33. O'Connell J, Lynch L, Cawood TJ, et al. (2010) The relationship of omental and subcutaneous adipocyte size to metabolic disease in severe obesity. PLoS One 5, e9997.

34. Appleton DJ, Rand JS \& Sunvold GD (2000) Plasma leptin concentrations in cats: reference range, effect of weight gain and relationship with adiposity as measured by dual energy X-ray absorptiometry. J Feline Med Surg 2, 191-199.

35. Ishioka K, Omachi A, Sasaki N, et al. (2009) Feline adiponectin: molecular structures and plasma concentrations in obese cats. J Vet Med Sci 71, 189-194.

36. Van de Velde H, Janssens GPJ, Cox E, et al. (2010) Chronic obesity in cats does not lead to a systemic low grade inflammation. In The Waltham International Nutritional Sciences Symposium: Pet Nutrition - Art or Science? p. 36

37. Tilg $\mathrm{H} \&$ Moschen AR (2008) Role of adiponectin and PBEF/ visfatin as regulators of inflammation: involvement in obesity-associated diseases. Clin Sci (Lond) 114, 275-288.

38. Tan HY, Rand JS, Morton JM, et al. (2011) Adiponectin profiles are affected by chronic and acute changes in carbohydrate intake in healthy cats. Gen Comp Endocrinol 172, 468-474

39. Verkest KR, Rand JS, Fleeman LM, et al. (2011) Distinct adiponectin profiles might contribute to differences in susceptibility to type 2 diabetes in dogs and humans. Domest Anim Endocrinol 41, 67-73.

40. Verkest KR \& Bjornvad CR (2012) Understanding adiponectin in dogs and cats: a work in progress. Vet J 193, 4-5.

41. Tvarijonaviciute A, Martinez-Subiela S \& Ceron JJ (2010) Validation of 2 commercially available enzyme-linked immunosorbent assays for adiponectin determination in canine serum samples. Can J Vet Res 74, 279-285.

42. Sell H \& Eckel J (2010) Adipose tissue inflammation: novel insight into the role of macrophages and lymphocytes. Curr Opin Clin Nutr Metab Care 13, 366-370.

43. Spits H \& de Waal MR (1992) Functional characterization of human IL-10. Int Arch Allergy Immunol 99, 8-15.

44. Palou M, Priego T, Sanchez J, et al. (2009) Gene expression patterns in visceral and subcutaneous adipose depots in rats are linked to their morphologic features. Cell Physiol Biochem 24, 547-556.

45. Fried SK, Russell CD, Grauso NL, et al. (1993) Lipoprotein lipase regulation by insulin and glucocorticoid in subcutaneous and omental adipose tissues of obese women and men. J Clin Invest 92, 2191-2198.

46. Tchernof A, Belanger C, Morisset AS, et al. (2006) Regional differences in adipose tissue metabolism in women: minor effect of obesity and body fat distribution. Diabetes 55, 1353-1360. 